\title{
Impact of constitutional genetic variation in androgen/oestrogen-regulating genes on age-related changes in human prostate
}

\author{
Abdel-Rahmene Azzouzi ${ }^{1,5}$, Beatrix Cochand-Priollet ${ }^{1}$, Philippe Mangin ${ }^{1,5}$, Georges Fournier ${ }^{1,6}$, \\ Philippe Berthon $^{3}$, Alain Latil ${ }^{3}$ and Olivier Cussenot ${ }^{1,2,3,4,7}$ \\ ${ }^{1}$ CeRePP-EA3104, Université Paris VII, Génopole, 4 rue Pierre Fontaine, F-91000 Evry, France, ${ }^{2}$ Institut d'Anatomie, UFR Biomédicale des Saints \\ Pères, F-75006 Paris, France, ${ }^{3}$ UroGène, Génopole, 4 rue Pierre Fontaine, F-91000 Evry, France, ${ }^{4}$ Department of Urology, Hôpital Saint Louis, \\ F-75010 Paris, France, ${ }^{5}$ Department of Urology, CHU Nancy-Brabois, F-54500 Vandoeuvre, France, ${ }^{6}$ Department of Urology, CHU Cavale Blanche, \\ F-29000 Brest, France and ${ }^{7}$ Institut Universitaire de France, 11 rue Pierre et Marie Curie, F-75005 Paris, France \\ (Correspondence should be addressed to A Latil, UroGene, Génopole, 4 rue Pierre Fontaine, 91000 Evry, France; Email: a.latil@urogene.com)
}

\begin{abstract}
Objective: Benign prostatic hyperplasia (BPH) is the most common benign tumour in ageing men. While the etiopathology remains unsolved, a disruption in the endocrine/autocrine-paracrine prostatic homeostasis, involving steroid hormones, contributes to the pathogenesis of BPH. DNA polymorphisms in genes involved in hormone synthesis, signalling and metabolism may, therefore, be responsible for these changes. We have evaluated the correlation between specific genotypes in androgen- and oestrogen-regulating genes (AR, SRD5A2, CYP17 and CYP19), and age-related prostatic changes.

Methods: We have tested genetic susceptibility to morphological and pathological criteria in 195 French Caucasians, using allelic variants for candidate genes involved in androgen/oestrogen prostatic activity: androgen receptor (CAG repeats), $5 \alpha$-reductase type 2 (TA repeats, V89L and A49T mutations), A2 variant of the $17 \alpha$-hydroxylase (CYP17) and the simple tandem repeat polymorphism (STRP) aromatase (CYP19) polymorphisms.

Results: The A2 variant of $17 \alpha$-hydroxylase (CYP17) and allele 191 of STRP aromatase (CYP19) showed an opposite effect on age-related prostate hyperplasia: CYP17 being associated with increased risk of prostate enlargement and CYP19 with reduced risk. The $5 \alpha$-reductase type II variants studied did not show links with prostate hyperplasia. The androgen receptor gene CAG repeat length showed a low correlation with the increase of prostate weight, suggesting some effect on age-related prostate growth.

Conclusion: These results suggested that common variants of the CYP17 gene are associated with prostate enlargement and therefore may increase the risk of development of $\mathrm{BPH}$ in this population, while infrequent variants of the aromatase gene (CYP19) could be of a protective nature.
\end{abstract}

European Journal of Endocrinology 147 479-484

\section{Introduction}

Benign prostatic hyperplasia $(\mathrm{BPH})$ is the most common benign tumour in ageing men (1). The microscopic prevalence of BPH is fairly consistent across national and ethnic groups, increasing with age in all male populations (2). However, while age is the main determinant of these morphological changes in the prostate gland, the etiopathology of benign prostate enlargement remains unclear and needs further study. A better understanding of risk factors is thus expected to be determined, particularly from the development of molecular epidemiological studies of these complex diseases. Furthermore, identification of the genetic determinants in age-related changes of the prostate could provide insights for risk assessment, prevention and indicate new targets for $\mathrm{BPH}$ management.

$\mathrm{BPH}$ is a multifactorial and probably heterogeneous disease, involving environmental, endocrine and genetic factors. The study of the interactions between genes and multifactorial disease has expanded in recent years.

Highly penetrating genes involved in $\mathrm{BPH}$ are likely to account for only a relatively small proportion of the disease. However, the majority of cases of $\mathrm{BPH}$ cannot be explained by a single gene model. Other 
predisposing mutations with low penetrancy could confer a moderate increase in the risk of specific diseases but they are widespread in the general population. This is particularly true for polymorphisms in genes encoding enzymes or receptors involved in the endocrine control of prostate homeostasis during ageing $(3,4)$.

Previous contributions, using case control design approaches, have identified genetic polymorphisms in genes involved in steroid metabolic pathways as risk markers in BPH (4-6).

\section{Androgen receptor CAG polymorphisms}

One of the critical functions of the products of the androgen receptor gene is to activate the expression of target genes. This transactivation activity resides in the N-terminal domain of the protein, which is encoded in exon 1 and contains polymorphic CAG repeats. A shorter CAG repeat is associated with a higher level of receptor transactivation function, thereby possibly resulting in a higher risk of $\mathrm{BPH}$. These data were interpreted to suggest a possible association between the polymorphisms of the androgen receptor gene and the development of BPH (6-9).

\section{SRD5A2 gene variants (TA repeats, A49T and V89L)}

Conversion of testosterone in prostatic target cells to its metabolite and active androgen, dihydrotestosterone (DHT), is catalysed by the enzyme $5 \alpha$-reductase. Two genes encode the two $5 \alpha$-reductase isoforms. They are located on chromosomes 5p15 and 2p23 for isoforms type I and type II respectively.

The roles of the two isoforms in the adult tissue are still subject to controversy and it is believed that isoform type II predominates in the prostate. The possibility that different alleles of the $5 \alpha$-reductase type II (SRD5A2) gene may be associated with different levels of $5 \alpha$-reductase activity (4) and consequently different levels of prostate enlargement risk has motivated studies of the ethnic variation in allelic distribution of this gene. The first DNA polymorphism described for the SRD5A2 gene as a susceptibility determinant in prostate cancer is a TA dinucleotide repeat polymorphism in the $3^{\prime}$ untranslated region of the gene. Three alleles with 0,9 or 18 TA repeats have been considered but the 18 TA repeats are common only in Afro-American men (10).

The V89L mutation reduces steroid $5 \alpha$-reductase activity. This substitution is particularly common among Asians. The Leu allele has been associated with lower serum levels of $3 \alpha$-androstanediol glucuronide which is another product of $5 \alpha$-reductase activity (11).

\section{CYP1 7 variants}

CYP17 encodes the cytochrome P450c 17 $\alpha$-enzyme which catalyses steroid $17 \alpha$-hydroxylase/17,20 desmolase activities at key points in testosterone and oestrogen biosynthesis in both gonads and adrenals (12). The CYP17 A2 allele contains a $\mathrm{T}$ to $\mathrm{C}$ transition polymorphism in the $5^{\prime}$ promoter region that creates an additional SP1 (CCACC box) promoter site. The polymorphism is correlated with increased promoter activity in the CYP17 gene (13) and circulating testosterone levels in men and oestrogen levels in women. This A2 allele has been associated with increased risk of baldness, polycystic ovarian cancer and recently with prostate tumours $(14,15)$.

\section{CYP19 simple tandem repeat variants}

Constitutional genetic variation at the human aromatase gene, so-called CYP19, mapping to chromosome 15 q21 has been related to aromatase activity and breast cancer risk. The aromatase gene (CYP19) encodes the enzyme which converts testosterone to oestrogen. In the prostate, oestrogens interact potentially with oestrogen receptor- $\alpha$ in fibromuscular cells and with oestrogen receptor- $\beta$ in prostatic epithelial cells. A common high heterozygosity tetranucleotide simple tandem repeat polymorphism named STRP in intron 4 had previously been described suggesting that, on the one hand, the $171 \mathrm{bp}$ allele was associated with high breast cancer risk and, on the other hand, that the $191 \mathrm{bp}$ allele could be linked with a lower risk $(16,17)$. The role of oestrogens and aromatase activity in the development of BPH has been suggested and aromatase inhibitors have been proposed to target $\mathrm{BPH}$.

We have performed an association study on a homogeneous French Caucasian population using pathological prostatic phenotypes strictly defined by morphological features from surgical and autopsy prostate dissection in elderly men. The genetic variants of androgen- and oestrogen-regulating genes (AR, SRD5A2, CYP17 and CYP19) have been analysed in a multiparametric statistical process with age-related prostatic changes. We hypothesise that specific genotypes in androgen- and oestrogen-regulating genes are correlated with prostate hyperplasia, and could provide information relevant to the detection and prevention of PBH.

\section{Subjects and methods \\ Subjects and data collection}

Included, prospectively, in this study were 195 subjects identified through the Department of Urology and Anatomy at the University of Paris VII and Paris V between December 1997 and March 2000. To be eligible for the study the subjects had to be of French 
Caucasian ethno-geographic origin and informed consent had to be provided.

All subjects included in the study provided constitutional DNA and complete histopathological analysis of the prostate gland. Prostate glands were obtained by radical prostatectomy $(n=109)$ and from cadavers during autopsy $(n=86)$ using the same surgical technique. Measurement of the weight of the autopsy and the operation specimens was carried out with a standard weighing machine (Teraillon, Paris, France) immediately after removal. Prostate glands were characterised for their macroscopic and microscopic aspects by systematic sections from apex to prostate base. We divided the prostates into categories using a combination of the age-related morphologic changes (prostate weight).

\section{Genotyping}

Primers are designated by the nucleotide position (relative to AR, GenBank no. M23263; SRD5A2, GenBank no. L03843; CYP17, GenBank no. M31146; CYP19, GenBank no. M30798) corresponding to the $5^{\prime}$ position, followed by the letter $U$ for upper (sense strand) or L for lower (antisense strand). Primer pairs were chosen with the assistance of the computer programs Oligo 4.0 (National Biosciences, Plymouth, MN, USA) and Primer Express (Perkin Elmer Applied Biosystems, Foster City, CA, USA). The nucleotide sequences of primers are shown in Table 1.

PCR amplification was carried out in a final volume of $50 \mu \mathrm{l}$, containing $50 \mathrm{ng}$ DNA, $20 \mathrm{pM}$ of each primer, $100 \mu \mathrm{M}$ of each dNTP, $1.5 \mathrm{mM} \mathrm{MgCl}_{2}, 10 \mathrm{mM}$ Tris-HCl, $\mathrm{pH} 8.3,50 \mathrm{mM} \mathrm{KCl}$ and 1 unit Taq DNA polymerase.

DNA amplification was performed conventionally: samples were subjected to 35 cycles of amplification consisting of $40 \mathrm{~s}$ of denaturation, $30 \mathrm{~s}$ of annealing and $30 \mathrm{~s}$ of extension. The final extension step at $72{ }^{\circ} \mathrm{C}$ was for $10 \mathrm{~min}$. The annealing temperature was optimised for each primer set.
The sensitive Applied Biosystems model 377 DNA sequencing system (Perkin Elmer) was used to identify CAG repeats of the $A R$ gene, TA repeats of the SRD5A2 gene and STRP of CYP19. Dilutions of PCR products were optimised for each target gene and $1 \mu \mathrm{l}$ aliquots of each amplified product were added to $3.5 \mu \mathrm{l}$ deionised formamide containing $0.3 \mu \mathrm{l}$ of a molecular size marker (Genescan 500 ROX, Perkin Elmer, Courtaboeuf, France). The mixtures were heatdenatured and $1.5 \mu \mathrm{l}$ aliquots of each were loaded on $4 \%$ polyacrylamide/ $8 \mathrm{M}$ urea gel and run for $3 \mathrm{~h}$ at $1200 \mathrm{~V}$ in the sequencer. Primers $559 \mathrm{U}$ of $A R$ and $2334 \mathrm{U}$ of $S R D 5 A 2$ were fluorescein-labelled at their $5^{\prime}$ end by adding Fluorprime (MWG, Courtaboeuf, France) during oligonucleotide synthesis and the size of the different fragments was determined with Genescan 672 Fragment Analysis software (Perkin Elmer Applied Biosystems).

V89L missense substitution in the SRD5A2 gene and the $\mathrm{T}$ to $\mathrm{C}$ polymorphism in CYP17 detection were based upon restriction fragment length polymorphism analysis after PCR amplification.

The G to C substitution at codon 89 of the SRD $5 A 2$ gene leads to the loss of an Rsa-I restriction site. The upper primer $(974 \mathrm{U})$ leads to a single nucleotide substitution in the amplified product ( $\mathrm{G}$ mutated to $\mathrm{T}$ in position 987 ) in order to abolish a second Rsa-I site. Thus, the polymorphic allele of interest leads to the loss of a restriction site unique within the amplified fragment, and Rsa-I digestion readily identifies the genotype for each sample.

The $\mathrm{T}$ to $\mathrm{C}$ polymorphism in CYP17 creates a recognition site for the Msp-A1 restriction enzyme and MspA1 digestion identified a second allele (A2).

PCR products were, therefore, digested for $3 \mathrm{~h}$ at $37^{\circ} \mathrm{C}$ using either Msp-A1 or Rsa-I, separated by agarose gel electrophoresis and stained with ethidium bromide to identify the base pair change.

\section{Sequencing of PCR products}

Samples were screened for the A49T mutation of the SRD5A2 gene by PCR amplification with the primer

Table 1 Oligonucleotide primer sequences used for genotyping.

\begin{tabular}{|c|c|c|}
\hline Gene & Oligonucleotides & Sequence \\
\hline$A R$ & $\begin{array}{l}599 U \\
874 L\end{array}$ & $\begin{array}{l}\text { 5'-TCCAGAATCTGTTCCAGAGCGTGC-3' } \\
\text { 5'-ACTGCGGCTGTGAAGGTTGCTGT-3' }\end{array}$ \\
\hline SRD5A2 & & \\
\hline A49T & $\begin{array}{l}837 U \\
943 L\end{array}$ & $\begin{array}{l}5^{\prime} \text {-GGCTACGGGAAGCACACGGA-3' } \\
5^{\prime} \text {-ATCCCCGCGGGCACCGCGAA-3' }\end{array}$ \\
\hline V89L & $\begin{array}{l}974 U \\
1102 \mathrm{~L}\end{array}$ & $\begin{array}{l}\text { 5'-GCCACCTGGGACGTTACTTCTG-3' } \\
5^{\prime} \text {-TCCTTGGCGTTCCTCGGTGC-3' }\end{array}$ \\
\hline$(T A) n$ & $\begin{array}{l}2334 U \\
2482 L\end{array}$ & $\begin{array}{l}\text { 5'-CTCCCACAATGCTGATGAA-3' } \\
\text { 5'-CAGACACCACTCAGAATCCC-3' }\end{array}$ \\
\hline CYP17 & $\begin{array}{l}230 U \\
642 L\end{array}$ & $\begin{array}{l}\text { 5'-CATTCGCACTCTGGAGTC-3' } \\
\text { 5'-GGCTCTTGGGGTACTTG-3'3 }\end{array}$ \\
\hline CYP19 & $\begin{array}{l}594 U \\
766 \mathrm{~L}\end{array}$ & $\begin{array}{l}5^{\prime} \text {-TTATGAAAGGTAAGCAGGTACTTAG-3' } \\
5^{\prime} \text {-GTCGTGAGCCAAGGTCACT-3 }\end{array}$ \\
\hline
\end{tabular}




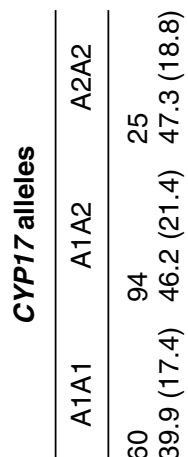

कळ

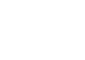

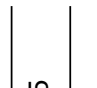

全全

L -

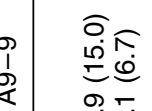

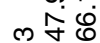

เกิว

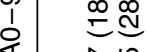

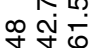

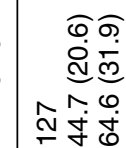

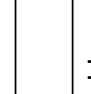

ชิ

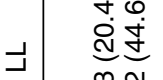

悉

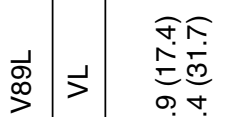

齐守

ช下

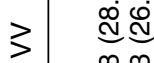

कิ ชं

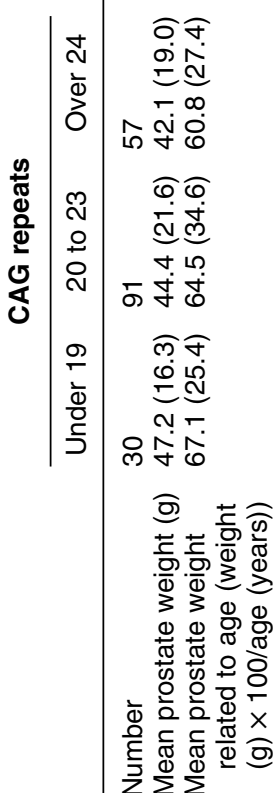

set $837 \mathrm{U} / 943 \mathrm{~L}$. The 107 PCR fragment was purified and sequenced using the Applied Biosystems (ABI) PRISM Big Dye Terminator Cycle Sequencing kit (Perkin Elmer) on the Applied Biosystems model 377 DNA sequencing system (Perkin Elmer). Potential A49T substitution was confirmed by performing sequence analysis both on the sense and antisense strand.

\section{Statistical analysis}

Prostate weight or prostate weight related to age (prostate weight $(\mathrm{g}) \times 100 /$ age $($ years $)$ ) was tested for correlation as a continuous variable by logistic regression with CGA repeat number and by the Kruskal-Wallis test and Student's $t$-test with CYP17 and SRD5A2 genotypes or CYP19 allele groups as nominal variables.

In addition, the alleles of CAG had to be grouped as discrete traits. The following categories were used: $\leq 19,20-21-22-23, \geq 24$.

The alleles of the TA polymorphism were categorised as $\mathrm{TA}_{0}$ and $\mathrm{TA}_{9}$ according Reichardt et al. (10), since no $\mathrm{TA}_{18}$ alleles were observed.

The statistical analyses were carried out with the PC program Stat View (SAS Institute, Cary, IN, USA).

\section{Results}

\section{CAG repeats}

Both weight and weight related to age showed correlation of CAG repeat number with coefficient of correlation $\mathrm{R}^{2}=0.01 \quad(P=0.1823)$ and $\mathrm{R}^{2}=0.006$ $(P=0.3025)$ respectively (Table 2$)$. An association between these parameters could be evoked but did not reach statistical significance.

\section{CYP17}

As shown in Table 2, the A2 variant was associated with weight and weight related to age $(P=0.039)$. The Student's test conducted on allele A1A1 $(n=60)$ versus A1A2 and A2A2 $(n=119)$ showed even better significance with $P=0.0226$.

\section{SRD5A2}

No difference was observed between SRD5A2 genotypes analysed (A49T, V89L or TA repeat) and prostate weight or age-related prostate weight (Table 2).

\section{CYP19}

As shown in Table 2, the prostate weight and the agerelated prostate weight were significantly lower in the 191 allele group $(P<0.01)$. It is noteworthy that the age of the subjects with allele 191 (72 years old, 
S.D. $=9$ ) was not statistically different from subjects with other CYP19 alleles (71 years old, s.D. $=10$ ).

\section{Discussion}

This paper is based on multiple correlations between allelic variants in genes involved in the androgen pathway and phenotypes in the age-related changes observed in the prostate. We performed a study on age-related prostatic enlargement, including an autopsy series in elderly men with their potential association with androgen/oestrogen-regulating genes.

The prostate is a hormonally regulated organ (18). Men with androgen metabolic pathway deficiency have been recognised as very low risk subjects for developing BPH. It is possible that a large proportion of familial aggregation is due not to segregation of mutations in a few major genes but rather to familial sharing of alleles at many loci, each in itself exerting only a small risk effect. The fact that genetic heritability explained $70 \%$ of the variance of plasma levels of androstanediols in male twins suggests that familial clustering may be due, at least in part, to familial correlation with hormonal status (19). These observations and previous reports on hormonal carcinogenesis suggest that functionally relevant sequence variants in genes involved in androgen metabolism and targeting receptors could define high-risk or low-risk profiles for age-related prostate hyperplasia.

Inherent difficulties in studies involving various ethnicities probably explain the discrepancies obtained in the different studies. Cases of BPH are frequently selected from patients undergoing surgical procedures consecutive to miscellaneous histopathological lesions associated with lower urinary tract symptoms.

\section{Genetic susceptibility and phenotypic variations in age-related prostate hyperplasia}

We report, on the one hand, that men who carry the A2 variant in CYP17 are more likely to exhibit agerelated prostate hyperplasia and, on the other hand, that men who carry the 191 allele in CYP19 have a low risk of prostate hyperplasia (Table 2). The hypothesis that CYP17 and CYP19 may be involved in agerelated prostate growth is based on our knowledge of testosterone synthesis and its metabolism to oestrogen. The product of CYP17 is responsible for testosterone biosynthesis. Testosterone is either transformed to DHT by the $5 \alpha$-reductase gene to act on androgen receptors or into oestrogen by aromatase (CYP19), both of which have been suggested as targets for $\mathrm{BPH}$ treatment. In a recent report, the polymorphism of CYP17 ( $\mathrm{T}$ to $\mathrm{C}$ transition in the promoter region) had no association with prostate volume; however, the CYP17 wild-type (A1/A1) genotype had a higher stroma/epithelium ratio than those with $\mathrm{A} 1 / \mathrm{A} 2$ and A2/A2 genotypes (20).

Although not confirmed by a case control collection of men from Northern Europe, previous studies support the role of the CAG repeat in the development of BPH. Giovannucci et al. (7) found an inverse correlation between androgen receptor gene $\mathrm{CAG}$ repeats and prevalence of surgery for $\mathrm{BPH}$ and enlarged prostate. Mitsumori et al. (8) examined CAG repeats lengths in $\mathrm{BPH}$ patients who underwent prostatectomy. A statistically significant $(P<0.02)$ trend for large adenoma size with short CAG repeat length was found. Conversely, Bousema et al. (5) found a similar mean number of CAG repeats in the androgen receptor gene in patients (21.8) and controls (21.9). They concluded that even if an association could exist between BPH and CAG repeat polymorphism, it is probably weak. In our hands, no significant correlation between CAG repeat length and prostate hyperplasia was observed. However, some statistically non-significant magnitude effects showed a low but suggestive correlation between CAG repeat length and age-related increase in prostate weight.

We also report that the SRD5A2 genotypes (V89L, A49T and TA repeats) had no significant impact on age-related prostate hyperplasia.

\section{Conclusion}

Interest in constitutional genetic variation is based on the possibility of identifying population subgroups that are at increased risk of developing BPH. In addition, knowledge of androgen metabolic enzymes or receptor gene genotypes can be used for chemopreventive strategies in BPH. Our study provides some evidence that genes comprising the steroid biogenesis pathway appear to be involved in age-related prostate gland growth, but their role on direct genesis still remains unclear. These observations are in agreement with the concept that androgens promote prostate growth. The association of no increased age-related prostate hyperplasia with CYP19 variants supports the development of aromatase inhibitor trials for the prevention of prostate hyperplasia. These results confirm the need for molecular screening and a pharmacogenomic approach in order to discriminate good candidates for chemoprevention in the common agerelated prostate diseases.

\section{References}

1 Boyle P, Gu PL, Jacobsen S, Ogawa O, Oishi K, O'Relly P et al. Epidemiology and natural history of benign hyperplasia. In 4th International Consultation on Benign Prostatic Hyperplasia (BPH), pp 25-59. Eds L Denis, K Griffiths \& S Khoury. Plymouth, UK: Health Publication Distributors Ltd, 1998. 
2 Berry SJ, Coffey DS, Walsh PC \& Ewing LL. The development of human benign hyperplasia with age. Journal of Urology 1984 $132474-479$.

3 Henderson BE \& Feigelson HS. Hormonal carcinogenesis. Carcinogenesis $200021427-433$.

4 Novelli G, Margiotti K, Sangiuolo F \& Reichardt JK. Pharmacogenetics of human androgens and prostatic diseases. Pharmacogenomics 20012 65-72.

5 Bousema JT, Bussemakers MJ, van Houwelingen KP, Debruyne FM, Verbeek AL, de La Rosette JJ et al. Polymorphisms in the vitamin D receptor gene and the androgen receptor gene and the risk of benign prostatic hyperplasia. European Urology 200037 $234-238$

6 Shibata K, Hirasawa A, Moriyama N, Kawabe K, Ogawa S \& Tsujimoto G. Alpha 1a-adrenoceptor polymorphism: pharmacological characterization and association with benign prostatic hypertrophy. British Journal of Pharmacology $1996 \mathbf{1 1 8}$ 1403-1408.

7 Giovannucci E, Platz EA, Stampfer MJ, Chan A, Krithivas K, Kawachi I et al. The CAG repeat within the androgen receptor gene and benign prostatic hyperplasia. Urology $1999 \quad 53$ $121-125$.

8 Mitsumori K, Terai A, Oka H, Segawa T, Ogura K, Yoshida O et al. Androgen receptor CAG repeat length polymorphism in benign prostatic hyperplasia (BPH): correlation with adenoma growth. Prostate 199941 253-257.

9 Habuchi T, Liqing Z, Suzuki T, Sasaki R, Tsuchiya N, Tachiki H et al. Increased risk of prostate cancer and benign prostatic hyperplasia associated with a CYP17 gene polymorphism with a gene dosage effect. Cancer Research 200060 5710-5713.

10 Reichardt JK, Makridakis N, Henderson BE, Yu MC, Pike MC \& Ross RK. Genetic variability of the human SRD5A2 gene: implications for prostate cancer risk. Cancer Research $1995 \mathbf{5 5}$ 3973-3975.

11 Makridakis N, Ross RK, Pike MC, Chang L, Stanczyk FZ, Kolonel LN et al. A prevalent missense substitution that modulates activity of prostatic steroid 5 $\alpha$-reductase. Cancer Research $1997 \mathbf{5 7}$ $1020-1022$.
12 Brentano ST, Picado-Leonard J, Mellon SH \& Miller WL. Tissuespecific cyclic adenosine 3', 5'-monophosphate-induced, and phorbol ester-repressed transcription from the human P450c17 promoter in mouse cells. Molecular Endocrinology $1990 \mathbf{4}$ 1972-1979.

13 Kadonaga JT, Jones KA \& Tijian R. Promoter-specific activation of RNA polymerase II transcription by SP1. Trends in Biochemical Sciences $19861120-23$.

14 Carey AH, Waterworth D, Patel K, White D, Little J, Novelli P et al. Polycystic ovaries and premature male pattern baldness are associated with one allele of the steroid metabolism gene CYP17. Human Molecular Genetics 19943 1873-1876.

15 Gsur A, Bernhofer G, Hinteregger S, Haidinger G, Schatzl G, Madersbacher $S$ et al. A polymorphism in the CYP17 gene is associated with prostate cancer risk. International Journal of Cancer 200087 434-437.

16 Kristensen VN, Andersen TI, Lindblom A, Erikstein B, Magnus P \& Borresen-Dale AL. A rare CYP19 (aromatase) variant may increase the risk of breast cancer. Pharmacogenetics $1998 \mathbf{8} 43-48$.

17 Siegelmann-Danieli N \& Buetow KH. Constitutional genetic variation at the human aromatase gene (CYP19) and breast cancer risk. British Journal of Cancer 199979 456-463.

18 Huggins C \& Hodges CV. Studies on prostatic cancer. Cancer Research 19411 293-297.

19 Meikle AW, Stephenson RA, Lewis CM, Wiebke GA \& Middleton RG. Age, genetic, and nongenetic factors influencing variation in serum sex steroids and zonal volumes of the prostate and benign prostatic hyperplasia in twins. Prostate 199733 $105-111$.

20 Schatzl G, Gsur A, Bernhofer G, Haidinger G, Hinteregger S, Vutuc $\mathrm{C}$ et al. Association of vitamin D receptor and 17 hydroxylase gene polymorphisms with benign prostatic hyperplasia and benign prostatic enlargement. Urology 200157 567-572.

Received 6 March 2002

Accepted 17 June 2002 